\title{
FB, THEY AND ME - THE ATTEMPTS OF USING SOCIAL MEDIA AS TOOLS FOR REFLECTIVE LEARNING AND COMMUNICATING AT THE UNIVERSITY
}

\author{
Lidia Bielinis \\ Department of General Pedagogy, University of Warmia and Mazury in Olsztyn, Poland
}

\begin{abstract}
The concept of reflective learning focuses on the idea of analysing the practitioners' experiences and the way they can learn from them. Considering the higher education, the author decided to describe students' and academic teacher's experiences related to learning and communicating through closed groups on Facebook. The three words: FB, they, me are deliberately put together in the title of this article. The experiences were collected to analyse the authors' own teaching methods and to determine the best learning outcomes by academic teachers and students. The methods of collecting data were mainly based on individual, Internet interviews. As a theoretical concept, the author referred to reflective learning models introduced by (among others) D. A. Schön, T. Borton, D. A. Kolb and G. Gibbs as well as to the theory of transformative learning and Connectivism.
\end{abstract}

Keywords: Connectivism, Facebook, higher education, reflective learning, social media, students' and teachers' experiences, transformative learning.

\section{Introduction}

\section{Academic didactics meanders - in which direction?}

One of my inspirations to write this text was the Professor Czachorowski's article published recently on edunews.pl portal, in which the author brings up a new spirit to very well-known methods of noting at the University. In his proposal, the notes can be prepared graphically, but without using computers or Internet. He emphasises the significance of preparing notes pictorially and what is more important - manually, like we used to do sometime time ago. Contemporarily, the advanced technology allows people to use electronics on a broad scale in education. In this part of the text, the considerations will be mainly focused on academic education perspective which perhaps, as Czachorowski argues, stopped dead in the stage of traditional notebooks, where students write down their thoughts in words or in the stage of Power Point presentations which 
are constantly read by the academic teachers during the lectures (Czachorowski, 2016).

As a younger-generation representative of academic teachers and a researcher interested in the area of digital phenomena in higher education, I reluctantly enforce traditional methods of working with students during practical classes. It does not happen to me to dictate or read during classes. It is important for me for several reasons. First of all, throughout the process of becoming an academic teacher I have observed that students value being authentic and that they are more involved in the process of learning if they also may 'be themselves'. Creating any encasements around you when being inaccessible, distant and talking in an obscure jargon may generate unnecessary barriers between students and lecturers. Secondly, when I was observing my masters, I had a chance to verify my foregoing beliefs to the length of the learning process that a young academic teacher must unarguably take before she or he will be ready to deliver lecturers or conceptualisations that would be interesting to the extent in which someone would like to make a note. There is one more relevant reason why I do not, putting it more colloquially, 'force' students to make written notes and myself to read Power Points presentations during the classes. I am deeply intrigued how contemporary students, who often are the representatives of the digital natives generation (Prensky, 2001), do learn and also where and when the process of learning happen in the digital era? Thus, I decided to test something different in academic didactics, oppositional to both: the Czachorowski's proposal as well as the traditional way of teaching.

I established a closed group on Facebook for students of Pedagogy at the Department which I cooperate with ${ }^{1}$. At the beginning, the contact through the group was mainly based on informing them about the timetable changes, accepting students' excuses for their absence and posting them mandatory articles that had to be read for the classes. With time, however, I have realised that they started posting links with the articles found on the Internet, they scanned some texts, so others did not have to go to the library and they tried to negotiate between themselves the way the classes, which were mainly prepared by them, should look like. They also discussed which texts ought to be read before entering the class, some of them even tried to force others to participate in the Oxford-Style debate, which finally fell through. Moreover, they were determining the ethical issues

\footnotetext{
${ }^{1}$ I recently had a chance to visit a colleague who was in Spain at the internship in the framework of Erasmus+ Programme for $\mathrm{PhD}$ students. During this visit, I talked with several dozen students from all over the world who were participants of the student exchange programs. They were, generally, describing the way classes look like at the Spanish University and told me about some professors who create closed educational groups on Facebook with students. These open-ended discussions result in the idea of establishing a closed group on Facebook for the Polish students of Pedagogy at the Department which I cooperate with. The visit took place in summer holidays of 2016 and it had a private character, however, the experiences collected during the trip influenced my further didactic practice at the University.
} 
concerned with other unauthorised people's access to the group. Eventually, they even criticised desk arrangement at our Department class, which in their opinion reminded a traditional school furniture setting, and they decided that we should reconfigure desks, as they would be set in a one big square in the centre of the class, which one of them commented later: 'so now people may look in other people's eyes when they talk to each other'. After each class I published some pictures taken during each team presentation. Although, all of them agreed for their images to be published within the group, the issue of their safety was raised many times, as one of the most important, in the process of reflection on our classes. We were trying to take a reflection on most actions that took place during the semester. The attempt of peering the Facebook as a potential tool for learning and communicating at the University evoked my personal need of collecting the experiences and impressions that students had during the process of establishing the group and the process of being in virtual, closed educational-goaled group. I will definitely return to that thread of the story in the further part of the manuscript.

The second inspiration to write this work were my professional interests, which concentrate on learning theories, especially adults' education concepts. I have been continuously investigating the area of learning models and theories that would explain this unarguably relevant and contemporary topical phenomenon of digitalism. I found out some significant concepts of several academics. It seems that the concepts presented below may be related or may refer to the phenomena of digitalism, which have become an area of my explorations. I have, therefore, decided to characterise them briefly in this article.

The essentials of working on experiences were introduced by John Dewey, who was raised in the second half of the XIXth century within equality and fraternity spirit in the United States of America (Gutek, 2003). His early childhood and adolescence experiences based on democratic rules influenced his subsequent philosophical considerations and everyday educational practice. The Dewey's learning by doing concept and his beliefs that we need to contrast traditional, formal education to the so-called new experimental school have become a starting point for examining the term reflection (Gutek, 2003). The main goal of his experimental school, founded in Chicago, was to reconstruct individual's own experience so that he or she may develop his or her most valuably. In Dewey's understanding, the reflection is an attribute of an activity. It literally means, it is not only thinking, as we generally consider the word, but it is more like a specific, valuable way of acting. Dewey contrasts the reflective action to the routine action. In his analysis, the word 'reflection' contains two components - the first one is a reflective action based on three abilities: openmindedness, whole-heartedness, and responsibility. The other component represents the reflective thinking (Gore, 1987). The reflection concept introduced 
by Dewey provides for something more than only reflective thinking and acting. It refers to the socio-political and ethical aspects.

Later research works focused on the area of reflection led to the conclusion introduced by Schön $(1983,1987)$. In his point of view, we should consider the reflection process from two perspectives - reflection in action and reflection on action. The first one literally means critical thinking and experimenting during the concrete individual's action. In this process, a subject is constantly conscious of the undertaken actions but is not obliged to verbalise his or her thoughts. Reflection on action is verbalising, analysing and clarifying things or experiences retrospectively. It generally takes place in cooperation with other people (Perkowska-Klejman, 2013). The Schön's model may be considered within the academic context and allows a university teacher to observe his or her own work from the perspective of the self-evaluation process (Mizerek, 2010). The area of reflection was also mentioned in works of many other researchers. In Terry Borton's Developmental Framework, the reader discovers three symbolic steps of reflection summarised in the following questions: What? So what? Now what? (Perkowska-Klejman, 2013). We may also refer to David Kolb's Experiential Learning Cycle that is mainly based on reflection (Illeris, 2006) or Graham Gibbs' Reflective Learning Cycle (Gibbs, 1998) that consists in six stages of reflective learning. Considering the higher education, I feel obliged to mention Jack Mezirow's Transformation Theory (Mezirow, 1998). He states that the essence of adult education process is critical reflection that allows the subject to reach his or her thoughts schemes and tacit presuppositions that may limit his or her own development (Mezirow, 1998). Finally, the Connectivism concept recently discovered in Canadians' papers (Siemens, 2005) should be taken into consideration as well. The concept consists in informal learning process of individuals. If we agree with the representatives of Connectivism that the learning process of a contemporary digital society is based on different views, experiences and transferable skills, the latest knowledge that is also reliable and, what is more, if we admit that learning is not only a process of assimilating some information but primarily a process of creating the knowledge that integrates cognition as well as emotions in the process of coming to understanding, this would let us, at least to some extent, to the return to the Dewey's essential postulates. It may also be possible to establish something similar to his laboratory school in Chicago.

The semester, during which I made an attempt of working with students' groups through the Facebook, is coming along the end. I am really fond of feelings, thoughts and experiences that the students had within participation in the educational group. I asked them to answer a list of questions which seem relevant from the perspective of self-evaluation process of an academic teacher at the University. It also seems to be important for me because of the question that Professor Czachorowski raised in his article about old-fashioned, traditional 
academic didactic methods, which in his point of view stopped dead in the stage of reading Power Point presentations and preparing students' word notes. Although his idea concerning the visual thinking (polish 'ryślenie or 'myślografia') (Czachorowski, 2016) seems to be an alternative to the oldfashioned methods, I am not trying to undermine his proposal despite the fact I am not testing it. I have to admit, however, that I perceive his point of view as a perfect inspiration for reviewing academic didactics in general; in this text I focus on the reflection on self-taken action, according to the established educational group on Facebook, which unarguably means leaving behind the traditional model of learning at the University.

\section{Entering the Internet sphere - research}

To order my reflections related to my initiative of creating closed groups on Facebook, I performed a self-evaluation of this action. It is a research that focuses on collecting data on the course and results of the author's own work. Information collected in this way is the basis for judging the value of actions taken and improving one's skills (Słownik Pojęć Systemu Ewaluacji Oświaty - Dictionary of Notions of Education Evaluation System). In this case, I used conclusive evaluation (Mizerek, 2010), which, in accordance with its assumptions, allows for collecting a lot of data during the action and after its completion. In the presented case, the most important objective of the test was to analyse bilateral experience related to the functioning of a discussion group on Facebook. Knowledge collected in this way was used to determine the possible ways of using Facebook for educational purposes at the University. My intention was also to draw conclusions that would provide foundations for further work with students so that it brings the best effects. To achieve this, I adopted a range of criteria needed to analyse the actions taken. I focused on several problem areas. I was mostly interested in finding answers to the following questions: 1/ What kind of experience related to the creation of a group on FB is regarded as valuable? 2/ What does communication mediated by the computer bring into the learning process? and 3/ What are students' opinions on the form of work using a closed group on FB?

To collect empirical material, I used data triangulation, which allows for better understanding of emerging categories and their properties (Konecki, 2000) and made it possible to find answers to the previously-asked questions. As the initiator and a member of the group at the same time, I started my research from participatory observation (Kozinets, 2012) during the semester. My actions mostly involved observing what activities were undertaken by students in the created closed group and analysing their reactions to posts, PDF files, links, and photos that were published there. Proposing to students the creation of a Facebook 
group together with their lecturer seems like a novelty that required special focus on the actions taken by students in various areas. Amongst other things, as regards reactions to learning materials, educational trivia and videos published in the group and also observing their behaviour in relation to the relatively informal and fast form of communication between them and myself. A broad range of behaviours - from no reaction through liking posts to the students' own activity in the discussion group - was a starting point for further research. Being in touch with my students through the discussion group, I decided to use this online tool to collect their statements on the impressions and feelings about the group. For this purpose, I posted a Word file with a semi-structured interview guide (Konarzewski, 2000) in the group and asked the students to complete it. Completed guides were delivered in two ways: electronically (by e-mail) or personally (as a sheet completed by hand). My action was aimed at ensuring maximum anonymity for the participants and preventing their opinions and feelings from being spread in the group. In this way, I collected 28 individual responses. The guide included questions concerning, amongst other things, their attitude towards the participation in such a group, the changes that occurred in it during the semester, the experience related to communication through the group, the availability and usefulness of learning materials and the nature of relations with the lecturer through the group, and finally a sense of security and innovativeness of this method. I used axial coding for data analysis, which allowed me to generate the most important categories from the point of view of the previously-asked research questions and to identify the relationships between them (Konarzewski, 2000).

\section{Social media at the University - research results}

\section{Getting used to the idea}

The gathered statements clearly show the issue of the students' emotional attitudes towards the idea of establishing the group. Their previous experiences (or their absence) related to being in a Facebook discussion group together with a lecturer generally evoked two types of reactions in students: surprise or a positive response to the idea. Some statements reflecting previous experiences of the participants and their initial feelings are presented below: I had no contacts with such groups before (...). My first thought was: "but how, with a lecturer in a group? It's pure madness" (PilnyStudent). I had no previous experience with a group that also included the lecturer (...) I liked the initiative, it was something new (GALLANONIM). There are no such initiatives at the University (...) during my entire studies I have not met with such an idea. (...) I thought it was a very good idea to exchange information with the person conducting classes and with other students (...) (Andzia). Frankly speaking, I have met with such an idea for 
the first time during my studies (...). I thought it was an innovative, very interesting idea (Nyx). Those opinions are reflected in a further evaluation of being in the group as a positive experience. The participants confirmed their belief that establishing the group was a good idea, or indeed, emphasised the importance of the experience of being in the group for their further positive approach to the idea. The statements of the students revealed some unfavourable and even critical voices, proving the change of their attitude during the semester, for various reasons. In spite of their previous optimism, students declared later: I believe that the group was established out of the needs of the lecturer - not the students (Pencil). It was influenced by articles in GW (Gazeta Wyborcza ${ }^{2}$ - a note by author), which slightly weakened my interest in the content published. I believe that there were too many ideological issues published in the group (Amelia). My approach changed during the semester, I was slightly put off by the mass of information (Magda). The definite majority of the students' statements prove their enthusiasm at the beginning, during and at the end of the activity undertaken. They emphasise the novelty, innovation of this method and the directness of contacts established through FB: I thought from the very beginning that it was a cool and modern idea (...) I approached it as a chance to try new methods (studentkaopiek.), I thought it was a good idea to have contact with everybody and a good method of communication (JAMAj.), (...) an innovative, very interesting idea (Nyx).

The collected material did not reveal any issues related to getting used to the Facebook portal as a tool for learning and communication. This can prove that FB discussion groups are commonly used for maintaining contacts among students. The only novelty is the fact of active participation of the lecturer in one group with the students.

\section{Openness to novelty and independence?}

The subsequent stage consisted in an analysis of the content of the statements provided by group participants regarding the impact of other students on their approach towards the idea of creating a group together with the lecturer. They mentioned that their peers also liked the idea. With full conviction, they declared that the approach of other participants had no effect on their initial perception of the group. However, there were two statements proving that not everybody approved of such an idea: I know that other students were not enthused about the idea, but over time, they became convinced (...) (Magda). My friend commented on this idea in a not very enthusiastic manner, but, generally, the opinions were

\footnotetext{
${ }^{2}$ Gazeta Wyborcza is a social and political journal published in Poland. The issue mentioned by the student is of importance due to changes in the political arena which took place in Poland last year. The reforms introduced in our country in the latest months by the Parliament many times have evoked antagonistic reactions of Poles. Polish media (both the television and the press) are not neutral as to commenting on the events, they also seem to categorically stand by either the ruling party or the opposition parties.
} 
positive (Blondi123). It may seem that the students demonstrate an autonomous attitude; they are independent in taking decisions and open to novelties. Nevertheless, although most of them declared initial enthusiasm (in completed interview guides), they perhaps were initially not fully convinced about the advantages of the initiative undertaken.

\section{A hindrance or an improvement?}

Most of the surveyed students did not perceive any difficulties related to the functioning of the group on FB. Some inconveniences experienced by them included: problems with public expression of one's own belief on the Internet: Public expression of one's own opinion even in the Internet is often difficult (ANONIMEK), with expressing opposite opinions: expressing one's own opinion/belief which may be different from the others (paplina12345), or retrieving specific information from many other posts published in the group: It was difficult do differentiate between important and additional information (mk1394). Too many links, news, with the control of which I sometimes had problems (PilnyStudent). On the other hand, participants perceived the group as a great convenience not only as regards rapid communication and contact with the lecturer, but, first of all, as regards the flow of information and educational materials contained in posts: The group is useful for the rapid flow of information and knowledge (paplina12345), (...) the group proved useful in searching for materials (mk-1394). Despite a definitely longer list of advantages of being in the group, the collected material did not allow at this stage to clearly establish the degree to which the discussion group could be useful.

\section{Visibility - integration continuum}

Unquestionably, Facebook facilitates the rapid flow of information and improves communication both between class participants themselves as well as between the participants and the lecturer. Frequency, efficiency, speed, simplicity and visibility are the words that best render the impressions described by students. Facebook enables checking the number of views of a given post on an ongoing basis, which provides immediate information on how many class participants have read the information. Posts reach everybody at once. They are not read through the intermediary of the group leader or an e-mail, which can be read, only by logging onto one's mail account. One of the students described it in these words: Facebook is always on, which ensures that given information will be seen in the group (JAMAj.). Using the group communication, distortion of the transferred information is avoided. The statement of one class participant confirms this: (...) the group reduces emergence of contradictory information (gossip) (student1). Communication through the FB group has one more value it can, to some extent, overcome barriers in communication by students. These reflections were confirmed by the following statements provided by the students: in the discussion group, everybody can express their opinion where, for example, 
in the class they were not able to make any attempt to discuss, since they are shy (studentka pedagogiki), (...) we could share opinions on a given subject (Andzia), (...) persons who do not speak in the class often participate in the group (student1). Posts of participants placed in the discussion tab were often received as a willingness to help others. Sometimes students published scans of texts to be read for the class, on other occasions they followed a discussion about a team in which individual people work. The response to such activities meant for some of them support, which is reflected by the following statements (...) everybody helps each other (Magda). What was good was that everybody actively participated in the group (wenig). Most people helped each other (studentkaopiek.). Classmates immediately wrote to me at the Facebook chat about any news in the group (TuPatka K.). The gathered material revealed another issue concerning building relations and integration through the FB discussion group. Several students did not experience any improvement as regards communication or maintaining relations with others through participation in the group. However, many of them admitted that computer-mediated communication can favour building relations and maintaining them, and that it serves integration of the entire group: $M y$ contacts with the group did not improve to any noticeable degree (...), but I am aware of the fact that through common writing and discussion, a certain thread of understanding can be created (PilnyStudent), I believe that Facebook generally is a site to keep relations; it favours establishing contacts in an easy way (Nyx), Facebook has a positive effect, maintains relations at a higher level than only meetings in the class (Amelia), (...) the group can integrate its members (student1), The group has not perhaps so much effect on maintaining the contacts, as on establishing the contact (...). This is how bonds emerge (Blondi123). The statements quoted above are important also in view of the fact that they were made by students in the first year of master degree studies, who generally do not know each other. According to their statements, the suggestion of creating a FB course group could have a moderate effect on the establishing of initial relations, getting to know each other and integration of all participants.

\section{Non-traditional teacher and the subjectivity of students}

The nature of relations entered into between students and lecturers (although this is an individual matter) is usually formal. So far, students used to contact me by e-mail, and in rare cases, I provided them with my mobile phone number (most often only to the leader of the group). The fact of participating in one FB discussion group with the students contributed, in my case, to transformation of contacts with them. In my belief, the relations gained new meaning. They asked questions concerning various issues, consulted me about their presentations, or asked me to provide texts for classes in a PDF format, or sometimes simply excused their absence or shared difficulties they encountered while conducting "mini-research" in the field before presentation. The collected research material 
made it possible to examine their perception of these specific relations that were new for both sides. Some statements prove the fact that Facebook does not generally affect changes in the nature of relations, such statements as: Neutral (stped9). The contact the same as in the class (TuPatka K.) best reflect the feelings of some students related to the area under analysis. Most of them emphasised the partnership, directness and innovative nature of the relation built by us: I believe that it is a good way of showing the students that you can have good relations with the teacher, that the teacher is not only the one who is standing at the blackboard and shaking a warning finger at someone or giving failing grades (PilnyStudent). The relations were based on conversation, the contact was direct (Nyx), Partner relations with the lecturer (mk-1394). The very method of evaluating me as a "modern" person made us closer to the notion of subjectively treating each other: I believe that communication through Facebook makes the student feel more subjective. Because of this, I could personally feel that the lecturer was trying to adjust to our expectations (...) although it was a Facebook group, the respect of the student towards the teacher was maintained (Kasia). Such communication demonstrated a casual, modern style of being of a lecturer and high involvement in conducting classes (Blondi123). I thought that finally she is a lecturer from the modern age (TuPatka K.). We can always count on her, receive an answer, support and providing materials (studentka pedagogiki). In the opinion of some persons, the contact with the lecturers at the university can be difficult: Sometimes the contact with the teacher is not the best, while in the group it was very good (...) efficient, fast and nice (wenig). Not every lecturer is so modern as to introduce such a novelty to his or her previous habits. I am even sure that such an idea among some lecturers with whom I had the pleasure to work would be ridiculed (PilnyStudent). Still others emphasised the value of relations between us in view of the support often provided to them in preparing classes and my personal features. They indicated friendliness, enthusiasm, involvement and ambition. Although some of them did not experience any innovativeness in relations with me, the definite majority perceived the nontraditional model of communication and responded positively to it. One of the persons even declared that, to some extent, the attitude of the lecturer towards the students affected a change in her perception of the entire situation: The change in my attitude towards this initiative was affected by the teacher conducting our tutorials. Through observation of her, her approach and involvement in our discussion group and into conducting tutorials, I understood that such a group is something fresh and interesting than only writing polite e-mails to the lecturer, in which I always had to preserve the polite form. In our group, if I contributed to any conversations, I obviously kept the polite form, such as "Dear Lidia" or "Dear Teacher" and I also felt respect on the part of the lecturer, who expressed that in a very nice and modern way. I liked very much the very phrase "Thanks", 
which is rather reserved for closer relations, as it contributed something modern to our conversations. (PilnyStudent). While examining the collected material, a hypothesis can be made that social portals to some extent contribute to warming the relations between students and teachers, and change the previous perception of academic teachers from hardly accessible and alienated to open and close to the students.

\section{Non-traditional teaching materials}

Communication through Facebook with students was, for me, important also in view of the possibility of distributing materials and interesting news to the group in the field of pedagogy in an electronic form. As results from my previous experience, students of pedagogy rarely use the resources of the university library. This results, first of all, from the large distance between the social sciences faculty and the university campus where the library is located. It used to be a common practice for me to bring my own books from home to be photocopied or to provide them with ready-made copies of texts. In the process of planning my tutorials this year, I took into account the fact that I was going to propose to the students establishment of a Facebook group and I found some materials in an electronic version, to be able to send them to students at any time. From my perspective, this significantly accelerated the process of preparing for classes. As results from the students' statements, they attached great importance to educational materials published in the discussion group in the form of PDF articles, links to press articles, lectures of the experts in the fields, interviews and scanned texts. At the beginning, I was not sure about the value of teaching aids provided to them. Over time, I observed that they partially used them to prepare their speeches. What can be clearly seen in students' statements is the visible merging of two significant categories related to materials published in the group. First of all, they emphasised the fact of saving time, which they could spend on other activities, among which they mentioned studying: I did not have to search for those articles in the library (...). This shortened the time of preparing for tutorials. (Andzia). Publication of texts was of high importance. Because of that, I saved time and could read the texts more thoroughly (wenig). Secondly, what seems important is optimisation of the process related to searching for texts: It was huge time saver for me, as everything was available for everybody and, above all, legible (Magda). I think that this made it easier to reach the materials and, in consequence, we could spend more time reading the materials and we could always do something in our spare time, without the need to go to the library or the copy shop (studentka.po). One person was guided, apparently, by ecological motives, directly related to saving natural resources of the environment: Texts in the PDF form were of great importance to me, as I try to print as little as possible, I prefer to have the same things in an electronic version (PilnyStudent). Although it did not play a significant role in the analysed material, I would also like to quote a statement of 
a student who emphasised the fact of gathering all materials necessary for studying the subject in one place: When providing the materials in one place, we can return to them and we have them in one location, without the need to look for them in other places (paplina12345). Publishing educational materials available for all participants is of great importance for students who very often have to fulfil the role of parents, employees and students at the same time, which was mentioned in statements: I was able to have materials required for classes without leaving home and could read them easily, without running to the library, wasting time, which I don't have enough because of studies and work (paplina12345). I saved time, which I don't have much due to work and family. (STUDENT001).

Moreover, the students' statements under analysis unquestionably indicate the utilitarian value of the published materials in the learning process. Most students indicated that they definitely made it easier to study or to share information and knowledge: Texts that were obligatory were some of the most interesting I had an opportunity to read. Therefore I can easily say that they were very useful. They certainly helped me to study (PilnyStudent). They helped me to understand the given material, some materials were more difficult and some easier to read, so it is important to have a choice (among those materials) (paplina 12345). Sometimes there were interesting links also after classes (wenig). The materials were partially interesting. Always some of the articles or interviews proved necessary (ANONIMEK). Some articles were useful for me when I was doing my presentation (GALLANONIM). They were sometimes more and sometimes less helpful. It depended on the subject of the class (Mi24).

The knowledge of how, what and where students learn is one of the fundamental assumptions of the Connectivism idea proposed by G. Siemens (2005). The most recent and reliable sources and the ability to choose among different information provide the basis for development of human personal selfawareness. Construction of knowledge is based on various opinions and sources (Siemens, 2005). The assumptions of Connectivism in adult learning methods also include their active and creative participation in building knowledge and sharing information, supported by modern technologies. In the material under analysis, originating from interviews, I also observed a visible coupling between the motivational function and the function supporting learning, fulfilled by the established FB group. One of the students pointed out earlier links published in the group, leading to articles containing ideological contents which, as she further reported: permitted me to refer to the beliefs and opinions of persons actively contributing to the group, and sometimes encouraged searching for other content (Amelia). Another student pointed out the presence of motivators which, in effect, translated into supporting the learning process: The discussion group motivated me to work and reminded me that there is less and less time. It generally teaches cooperation, provides an opportunity to exchange opinions and to search for 
various information (studentka pedagogiki). Still another person wrote: The group certainly motivated me by adding articles (...). I started to pay attention to information on the Internet concerning education (STUDENT001). (...) I learnt creativity, involvement in broadening knowledge (stped9). Because of the group, I had an opportunity to extend my knowledge beyond the obligatory materials (ANONIMEK).

Generally, group participants had no qualms about publishing their own studies, presentations and scanned texts in the group. This was confirmed by the majority of statements, which indicate the need to cooperate and the ability to share with others: When I had something useful (...) and when I thought that it could be certainly useful for somebody, I was happy to be able to share something (JAMAj.). I believe that when I prepared something for the class and it was verified, then why not share it with others? Perhaps it may turn out handy for someone (PATKA $($ )). When I found an interesting text, which was worth sharing. This is a standard, you don't do it grudgingly, we are dependent on each other to some extent; persons who do not share, harm themselves. (student1). However, the fact that seemed alarming to me was that one person who in previous statements negatively commented on the initiative of creating the group, expressed her anxiety about publishing any content: I did not publish in this group (with the teacher) but only in the specialty group. I did not like to contribute to the forum of that group, since I felt that I would be evaluated by the teacher and I did not want that (Pencil). As results from that, closeness and openness in contacts with students and supporting their learning process does not always have to be perceived in a positive way and does not in every case help to escape from the commonly established power structure: a dominating teacher versus subordinate student.

\section{Traces left in the web - sense of security}

In the prepared interview guide, I included a whole range of questions related to the issue of feeling secure. They included four areas important from the point of view of this article. The first one concerned publication of the students' results of quizzes and tests in the closed group on Facebook. The second one included questions concerning opinions on the photos of participants that were published in our group after their presentations. Another area concerned the issue of tagging their first names and surnames in posts. The aim of the last one was to check to what extent the participants felt safer in the group after we verified the list of persons authorised to access it. Although a significant part of students had nothing against making the results of quizzes being made public in the discussion group, some of them considered it worthless or proposed specific solutions related to the feeling of security and anonymity in this regard. For instance, one of the participants put forward the following proposal: I believe that we can manage it in that way that the grades are given on the basis of the student ID number, and 
not with the name and surname (studetnkaopiek). Likewise, the opinions of making their image public in the FB group were varied. Although we agreed on this issue during our first class and all participants consented to making photos of them during their presentation and to publication of their image only in the closed group, some of them emphasised later either the pointlessness of this activity or dangerous consequences they saw in relation to such an activity: Good idea in a CLOSED GROUP. Dissemination outside the group should be strictly forbidden. Photos are good self-control, they help to control our own attitude during the presentation (student1). Photos - a good keepsake, but unnecessary (Amelia), I don't like it too much, as it does not contribute anything to my learning process. Besides, what you publish on the Internet, remains there forever; you can always remove the photo from the group, but you cannot remove it from the Internet (Magda). This last statement drew my attention to an important fact of infringing the boundaries of the sense of security of course participants. This issue seems to require particular care while planning further activities related to participation in online activities. However, the idea of tagging students' profiles in the group met with better approval and acceptance; the students did not see any problem with referring to them in the posts and using their first names and surnames. They also mentioned that it helped them to more quickly respond to information addressed directly to them. Initially, the discussion group also included persons from other tutorial groups, which generally were added by the students. I also added another lecturer who taught the same course as a member of the group. Over time, I thought I should ask the students about their willingness to verify the rights to access our group. I asked one of the students, our group admin, to perform it. Students accepted this idea and I had a feeling that they felt much safer from that moment. Their statements oscillated in a continuum: I did not feel entirely secure to I felt secure after verification of members. This is illustrated, for example, by such statements: The idea of verification was great. Persons who have nothing to do with the group should never be made a part of it. Ifelt that my image and data are better protected (Magda). I think that I felt better after verification (GALLANONIM).

Planning any educational activities on the web requires from the teacher a particular sensitivity to issues related to the students' feeling of security. The fact of drawing my attention to the publication of images in the group or the results of their surveys as not entirely appropriate activities is significant to the extent that it could affect the willingness to participate in similar initiatives in the future.

\section{Facebook and the need for its use in academia}

Despite a partially unfavourable evaluation of the idea of using the image of participants and carelessness as regards the publication of their test results in the group, students very positively responded to the idea of creating social media discussion groups with the lecturer in the future. In their statements, they declared 
the need to undertake initiatives of this type, highlighting their value and listed the advantages of functioning in the group. Among the most important advantages, they reported the experience related to rapid and immediate communication and the efficient course of the learning process. Some of them even proposed specific situations and university courses for which the use of the Facebook site would be justified: I would like such a group to be established for courses with which students have problems, e.g. methodology of social research (Andzia). (...) such a system of cooperation between the lecturer and the students makes sense (student1). This is a great solution for students and teachers, makes the work of the entire group easier (studentka94). An interesting reflection on the activity undertaken was made by one of the students: Such groups should be created in our times. The world and technologies are constantly improving, so we can also change this world and make learning easier (...) as such groups give more possibilities (studentkaopiek). Her statement refers to the essence of the Connectivism idea, and, namely, one of its principles which treats the learning process as one that can occur outside the human organs - in devices, society, network etc. (Siemens, 2005).

\section{FB, they and me (we)? - finding the link between student and academic worlds}

The conducted analysis made it possible to arrive at several important conclusions, on the basis of which I will be able to improve my teaching practice at the University. Below, I am trying to indicate those that are of the highest value from the perspective of self-evaluation of my own work.

First of all, proposing participation in the discussion group on Facebook to students does not involve any difficulty in getting used to this tool. The fact of the widespread use of this portal by students is unquestionable. The only novelty that emerged in the analysed material is co-participation in the group with the lecturer. However, this did not raise any objections from the students. Despite their initial surprise, most of them definitely supported the initiative undertaken and in effect began to perceive the teacher as someone from "their world", "their generation", close to them.

Secondly, participation in the group involves frequent online contacts, which, to a certain extent, can serve maintaining relations and even, as revealed in the texts analysed, help to develop bonds and integrate the group. Therefore, it seems particularly reasonable to propose creating such a group at the beginning of a given stage of studies, when the students are beginning to get to know each other.

A less formal nature of contacts maintained through the social portal between students and the lecturer favours breaking down the communication barriers and 
contributes to warming up the relations. Closeness, openness and accessibility of the teacher create a specific climate that serves building the subjectivity of the student. Certainly, it can be claimed that such a form of contacts cannot have a negative effect, it can be, as reported by students: "neutral". However, it must be admitted that even such an indirect form of communication does not always liberate us from the roles imposed on us: a dominating lecturer and a subordinated student. This is indicated in the statement provided by one of the participants, who did not dare to publish any posts in our discussion group out of fear of being graded by the teacher.

The most attention was paid to the issue of non-traditional learning materials, which, because of their useful nature, proved to be a highly important element in the process of studying. The fact of saving time and optimisation of the text search process was of a great value for students, first of all, in view of the fact of the various social roles fulfilled by them and the need to draw knowledge from various sources. The learning materials published on the group and additional links leading to interesting news in the field proved, from the perspective of some students, interesting and helpful when preparing for class activities, while from the perspective of others, they encouraged further search or their critical analysis. It seems important in relation to the analysed experiences of adults. The assumption of an academic education, particularly in humanities and social sciences, is to activate independent thinking in students, their ability to express doubts, skills in asking questions or questioning the rules established in the world. The education of adults is perceived in this manner by Jack Mezirow - the founder of the transformative learning theory (Mezirow, 1998). The group fulfilled, to a large extent, a motivational role in this regard and supported the studying process. Therefore, it is possible to collect interesting materials in an electronic form and to follow current events in the educational arena (domestically and abroad), which will then be published in the group. Before creating such a group, it is worth asking the question of what materials should be searched for to avoid ideological distortions and demagogy and to support the process of the harmonious development of an adult student.

The collected material also made it possible to draw certain conclusions related to the sense of online security. Reflecting on the means of notifying students of the test results, agreeing with them on the possibility of publishing their images in the group and a reflective approach to the issue of privacy management and membership in the group, provide starting points for building trust and a sense of security.

A positive approach of students towards undertaking such initiatives in the future reinforced my conviction about the sensibility of co-creating with them education and discussion groups on Facebook. It seems just like several years ago when electronic mail brought about a revolution in communication between 
students and lecturers; although its role in the latest years has been decreasing in relation to a growing participation in social networking platforms.

As a result of the activity undertaken, it was managed to expose the significance attributed by students to this new form of communication and learning. It is a fact that reflective observation of the digital space and the ability to participate in it together with students provides an extraordinary challenge and also requires that the teacher maintains a high level of subject matter knowledge and ethical standards.

\section{References}

Gutek, G. L. (2003). Filozoficzne i ideologiczne podstawy edukacji. Gdańsk: Gdańskie Wydawnictwo Psychologiczne.

Gibbs, G. (1988). Learning by doing: A guide for teaching and learning methods. Oxford: Oxford Further Education Unit.

Gore, J. M. (1987). Reflecting on Reflective Teaching. Journal of Teacher Education, MarchApril, 33-39.

Illeris, K. (2006). Trzy wymiary uczenia się. Wrocław: Wydawnictwo Naukowe Dolnośląskiej Szkoły Wyższej.

Konarzewski, K. (2000). Jak uprawiać badania oświatowe. Metodologia praktyczna. Warszawa: Wydawnictwa Szkolne i Pedagogiczne Spółka Akcyjna.

Konecki, K. (2000). Studia z metodologii badań jakościowych. Warszawa: Wydawnictwo Naukowe PWN.

Kozinets, R. V. (2013). Netnografia. Badania etnograficzne online. Warszawa: Wydawnictwo Naukowe PWN.

Mezirow, J. (1998). On critical reflection. Adult Education Quarterly, 48, 185-198.

Mizerek, H. (2010). Efektywna autoewaluacja w szkole - jak ja sensownie zaprojektować $i$ przeprowadzić, w: G. Mazurkiewicz (red.), Ewaluacja w nadzorze pedagogicznym. Autonomia, Wydawnictwo UJ, Kraków.

Perkowska-Klejman, A. (2013). Modele refleksyjnego uczenia się. Teraźniejszość-CzłowiekEdukacja, 1 (61), 75-90.

Siemens, G. (2005). Connectivism: A learning theory for the Digital Age. International Journal of Instructional Technology and Distance Learning, Vol. 2 No. 1, 3-10.

Schön, D. A. (1983). The reflective practitioner: How Professionals Think in Action. New York: Basic Booksp.

Schön, D. A. (1987). Educating the Reflective Practitioner: Towards a New Design for Teaching and Learning in the Profession, Oxford: Jossey-Bass Publishers.

Słownik pojęć Systemu Ewaluacji Oświaty, H. Mizerek (red.), [w:] http://www.npseo.pl/action/dictionary/make/view/item/54/ 